\title{
GOBERNANZA PARA EL DESARROLLO TURÍSTICO SOSTENIBLE EN LA COMUNIDAD ANDINA: \\ UN NUEVO RETO EN LAS RELACIONES UNIÓN EUROPEA-CAN
}

\section{Resumen}

El artículo comienza con un análisis de la situación de la actividad turística de la Comunidad Andina, con el objeto de mostrar, tanto su potencialidad, como algunas de sus limitaciones más importantes. Como organismo con competencias para la cooperación en terceros países, la UE se estudia desde la perspectiva de las relaciones que ha venido manteniendo con la CAN. Finalmente, este artículo presenta a la gobernanza como un nuevo reto, como una serie de postulados ligados a la cooperación y colaboración entre agentes turísticos, que la Unión Europea puede introducir en sus estrategias de ayuda a la Comunidad Andina, de manera que, aplicados a programas específicos de cooperación, fomenten en esta región el turismo como instrumento al servicio del desarrollo sostenible y la cohesión social.

\section{ALABRAS CLAVE}

Unión Europea, Comunidad Andina, desarrollo sostenible, turismo, gobernanza, cooperación, colaboración y participación.
Por:

Ana María Mazón*

Laura Fuentes Moraleda **

\section{INTRODUCCIÓN}

asta hace no demasiado tiempo, tan solo unas pocas naciones, de las consideradas en vías de desarrollo, creían en las posibilidades del turismo como una de las soluciones a sus múltiples problemas. Sin embargo, hoy el turismo es visto por muchos de estos países como la actividad capaz de generar riqueza en las economías menos favorecidas.

En la actualidad, como afirma Figuerola (1990), los países desarrollados se han convertido en los primeros emisores de turismo, lo que ha generado una correlación directa entre la actividad turística y el desarrollo económico.

* Licenciada en Administración y Dirección de Empresas por la Universidad Autónoma de Madrid. Coordinadora de los programas de grado del departamento de Turismo de la Universidad Antonio de Nebrija, la profesora Muñoz es consultora, llevando a cabo proyectos con organismos públicos y privados y especialmente con la Organización Mundial de Turismo.

* Licenciada en Economía por la Universidad Autónoma de Madrid. Profesora del área de gestión de destinos turísticos de la Universidad Antonio de Nebrija, Directora de promoción y marketing de los programas de postgrado. 
Por el otro lado, los países mal dotados de recursos productivos, pero poseedores de materias primas y otras riquezas sin explotar, han puesto sus ojos en la actividad turística como un modelo eficaz para promover y ayudar al desarrollo económico de su región.

El ejemplo de algunos países que han desarrollado determinados recursos turísticos para atraer grandes cantidades de turistas, ha servido de incentivo para otros destinos que se han planteado el estudio de sus recursos, para la posterior puesta en valor y explotación.

Pero el impacto económico que tiene el turismo en las regiones menos favorecidas no es la única razón de su impulso. Existe una serie de efectos indirectos e inducidos por la actividad turística, que redundan en una mejora de las condiciones socioculturales de las regiones.

El incremento de la actividad turística en una región generará unos ingresos en la zona, que finalmente, redundarán en el desarrollo de los pueblos. La mejora del nivel de vida de las regiones y la generación y redistribución de la riqueza han de ser los principales objetivos del desarrollo de una actividad, que en muchas ocasiones requerirá del impulso de organismos supranacionales, como la Unión Europea.

Este es el caso de la Comunidad Andina (CAN) que, con un alto potencial de recursos turísticos de tipo cultural y natural, encuentra en el turismo una alternativa al desarrollo económico de la región.

Al mismo tiempo, la literatura del pensamiento económico ha ido evolucionando hasta considerar que los aspectos socio-culturales de las regiones son elementos determinantes para el crecimiento y el desarrollo económico de los países.

\section{A bstract}

This article describes the situation of the Andean Community tourist industry with the aim to show its most relevant strengths and weaknesses. As an institution in charge to cooperate with third countries, the EU is studied from the perspective of relations established with CAN organizations. Finally, this agreement is considered a challenge related to the cooperation among tourist agents so that the European Union could apply them as one of the strategies to help the Andean Community, also using them in specific cooperation programs and consolidating the tourist industry as a service tool for sustained development and social cohesion.

\section{KEY WORDS}

European Union- The Andean Community- sustained developmenttourism- agreement- cooperationparticipation. 
Sin embargo, aunque gobiernos y sociedades como la andina quisieran alcanzar el desarrollo sostenible, no podrían hacerlo con facilidad, dado que las capacidades de acción colectiva, necesarias para hacerlo, distan de las que existen hoy día. Hay un claro déficit de capacidades institucionales ${ }^{1}$.

De este modo, el desarrollo turístico sostenible en el ámbito local debe partir de un proceso en el que la sociedad local, manteniendo su propia identidad y su territorio, genere y fortalezca sus dinámicas económicas, sociales y culturales, facilitando la articulación de cada uno de los componentes del sistema o la red turística y logrando una mayor intervención y control entre los mismos.

Para poder llevar a cabo este proceso, es fundamental la participación de todos los agentes o fuerzas turísticas que interactúan dentro de los límites del destino, los cuales han de contar con un proyecto común que combine generación de crecimiento económico, equidad, cambio social y cultural, sostenibilidad medio ambiental, enfoque de género y calidad de vida, entre otros.

La concepción del desarrollo turístico como un proceso de cambio social, debe incluir a todos los sectores económicos del destino y a todas las necesidades de la sociedad civil (desarrollo integrado), así como considerar fundamental la opinión y la participación activa y constante de la población a la que implica (desarrollo participativo).
Cada uno de los grupos de interés en un destino turístico manifiesta unos objetivos instrumentales distintos en el proceso de maximización de sus utilidades; sin embargo, la mayor parte de los mismos son compatibles entre sí, esto es, no se trata de juegos de suma cero, sino que a través de procesos de colaboración, los actores estratégicos en el destino podrían conseguir sus metas sin perjudicar a las del resto².

Sería conveniente hacer especial hincapié en la especificidad que manifiesta un destino turístico como espacio donde se producen un conjunto de interconexiones muy distintas. Si bien, se trata de un sector económico en el que las relaciones económicas o de mercado son la base que sustentan la actividad, por otro lado, existe un amplio número de relaciones entre diferentes grupos de interés que "a priori» no participan de dichos enlaces empresariales, pero que influyen en el desarrollo turístico del destino tanto o más que los primeros (fundamentalmente las que se refieren a la sociedad civil y a la administración pública) ${ }^{3}$.

En este nuevo marco relacional, la Unión Europea, en el seno de sus políticas de cooperación al desarrollo y ayuda al exterior, ha de potenciar, no solamente la mejora de las relaciones económicas entre agentes turísticos regionales o de estos para con la UE (acuerdos económicos y comerciales), sino que, si desea ir más allá del mero crecimiento económico del turismo y avanzar hacia un desarrollo equitativo para la CAN, ha

\footnotetext{
1 Capacidades institucionales públicas, sociales o privadas como el liderazgo, la paticipación social, la coordinación y cooperación, la prevención y gestión de conflictos, el acceso a la información y al conocimiento útil.

2 Situaciones de «win-win», esto es, donde ganan.

3 La sociedad civil entra en contacto con el turista y sufre las consecuencias o impactos que este provoca en el territorio. Así mismo, si el crecimiento turístico conduce al desarrollo, los ciudadanos tendrán la oportunidad de relacionarse con otras culturas al tiempo que las condiciones del destino podrían mejorar en lo que se refiere a infraestructuras, servicios, etc.
} 
de contribuir en sus políticas al fortalecimiento de determinadas relaciones sociales que resultan vitales para que el desarrollo turístico contribuya a la deseada cohesión social y a la sostenibilidad.

En definitiva, el objetivo de este artículo es el de señalar la potencialidad turística de la CAN, analizar las relaciones UE-CAN y definir cuáles son las estrategias que ha de seguir la UE para fomentar el desarrollo en la Comunidad Andina a través del fortalecimiento de sus políticas y de las acciones de cooperación en materia turística que favorezcan la cohesión social de la región así como la reducción de los desequilibrios y la pobreza.

\section{TURISMO COMO HERRAMIIENTO DE DESARROLLO PARA LA Comunidid Anidina. La Gobernanza all SERVICIO DEL DESARROLLO TURÍSTICO SOSTENIBLE. UNA ALTERNATIVA PARA LA COHESIÓN SOCIAL REGIONAL}

\section{El Turismo en la CAN. Un sector de alta potencialidad}

Tal y como se autodefine la propia Comunidad Andina $^{4}$, la unión voluntaria de estos países persigue alcanzar un desarrollo acelerado, equilibrado y autónomo, mediante la integración andina, suramericana y latinoamericana. Todo ello debería favorecer el impulso del turismo en la región, lo que generaría ingresos y riqueza para la población local y revertiría en un mayor bienestar $^{5}$.

En muchas ocasiones, el Consejo Presidencial Andino ha destacado la importancia del comercio de los servicios, recomendando a los países miembros que se adelanten en políticas y proyectos de cooperación económica y social en el área de turismo.
En 1982 se creó el Programa Andino de Desarrollo e Integración Turística, cuyo objetivo general era el de fomentar el desarrollo integrado del turismo entre y hacia los Países Miembros.

Algunos de los fines de este régimen fueron el fomento del turismo intrasubregional, fronterizo y hacia la subregión; la utilización del turismo como elemento de educación y promoción de la Comunidad Andina; la creación de conciencia ciudadana sobre la importancia económica y social del turismo para el desarrollo de la subregión; la conservación, recuperación y uso sostenible de los recursos naturales y culturales vinculados con el turismo y la mejora y diversificación de la oferta turística subregional, entre otros.

\footnotetext{
4 Tras el retiro de Venezuela en abril de 2006, la Comunidad Andina (CAN) está formada por cuatro países; Bolivia, Colombia, Ecuador y Perú. Esta organización regional, la más antigua de Latinoamérica, se basa en el Acuerdo de Cartagena de 1969, que estableció el «Pacto Andino»

5 Esto sería el resultado de un proceso de desarrollo turístico basa en los principios de la sostenibilidad y gestionado de manera conjunta por todos los actores sociales de la región. La realidad muestra que, en la mayor parte de la ocasiones, los beneficios de la actividad turística revierten en grupos sociales minoritarios y con las rentas más altas. Esto se convierte en un reto para los gobiernos nacionales y también para instituciones como la Unión Europea. Así, los proyectos turísticos que se financien a través de instituciones europeas deberán ser muy rigurosos en la definición de los impactos que estos van a tener en su conjunto.
} 
El Comité Andino de Autoridades de Turismo (CAATUR) fue creado el 25 de mayo de 1999 como organismo técnico asesor de la Secretaría General de la Comunidad Andina y está conformado por representantes de los organismos nacionales, responsables del turismo en cada país miembro.

El objetivo más importante de este comité es el de promover la elaboración y el desarrollo de programas de acción en materia de desarrollo turístico para que los flujos turísticos en la región crezcan y contribuyan al desarrollo integral de los pueblos.

En la XXVI Reunión Ordinaria de la CAATUR, el 16 de abril de 2007, se trabajó en aspectos tan dispares como la aprobación de la versión final del Proyecto Subregional de la Cuenta Satélite del Turismo (CST) o la presentación de los términos de referencia de proyectos relacionados con ciudades patrimonio de la humanidad (Bolivia), industrias culturales (Bolivia), transporte aéreo (Perú), etc.

Si bien todos estos propósitos de la CAATUR responden a una iniciativa de fortalecimiento del sector turístico en la región, sería necesario que se hiciese especial hincapié en la necesidad de hacer partícipes a todos los actores sociales en el proceso de desarrollo turístico de la CAN. En este sentido, proyectos orientados a fortalecer la confianza entre grupos o fomentar la cooperación entre agentes son un punto de partida prioritario para que el citado crecimiento turístico contribuya a un desarrollo equitativo.

A las reuniones de la CAATUR pueden asistir representantes del sector privado nacional y subregional y representantes de organismos internacionales que estén t interesados en el desarrollo y fortalecimiento del sector turístico andino. Este sería el cauce por el que la UE adquiriría la sensibilidad necesaria para potenciar más programas de cooperación en este ámbito, susceptibles de contribuir a la cohesión social entre actores de la región andina.

La Comunidad Andina ha experimentado una tendencia creciente hacia la actividad turística, reflejada en leves incrementos de las cifras de turismo emisor y receptor en los últimos diez años.

Los datos disponibles hasta el 2005 reflejan el incremento de turismo emisor respecto al turismo receptor desde el año 1998. Este cambio de tendencia puede deberse en parte a los movimientos migratorios que en los últimos años se vienen produciendo en los países de la Comunidad y que no quedan registrados, como tal, en los sistemas de estadística de cada uno de los países.

En cuanto a la procedencia de los turistas, desde 1995 han predominado los norteamericanos frente a los demás. Se destaca el incremento de los turistas japoneses respecto al resto, ya que en los últimos años se ha duplicado la afluencia. En cuanto al modo de acceso a la región, el $70 \%$ del turismo proveniente de fuera, accede a la misma, por vía aérea.

La actividad turística en la comunidad andina está proporcionando 3.130 millones de dólares (en 2004), cantidad que se ha ido incrementando en los últimos diez años con unas tasas de variación relativamente pequeñas.

Por su parte, la salida de divisas que genera la salida de ciudadanos andinos por turismo se redujo, de 3.329 millones de dólares en 1994 a 2.907 millones de dólares, con una tasa de crecimiento promedio anual de $-1,5 \%$. 


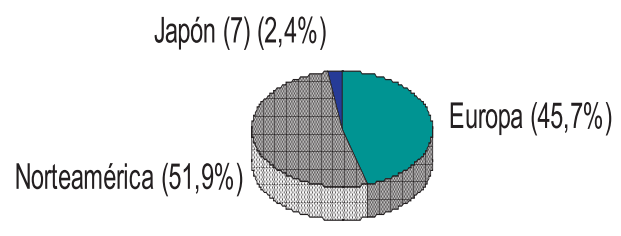

Fuente: Elaboración propia a partir de los datos proporcionados por la Comunidad Andina. www.comunidadandina.org

Según datos estadísticos proporcionados por la CAN, ha habido mayores salidas de divisas por turismo emisor, que ingresos de divisas por turismo receptivo desde 1994, lo cual ha sido desfavorable para la Balanza Turística de la Comunidad Andina. Esta presentó déficits desde 1.227 millones de dólares hasta de 345 millones de dólares en el año 2003. a excepción de los años 1997 y 1998 en los que se produjo un superávit de 89 y 71 millones, respectivamente.

El gasto per cápita promedio por turismo receptivo en la Comunidad Andina fue de 853 dólares en el 2003, mayor que el gasto per cápita promedio por turismo emisor que alcanzó en ese mismo año, 770 dólares. Ambos tuvieron una disminución con respecto al año 2002 (de $-10,3 \%$ y $-14,8 \%$, respectivamente $)^{6}$.

Del análisis de la actividad turística de la región país por país (Figura 2), el que registra mayor volumen de turistas durante el periodo es Perú. Hasta 1997, Colombia fue el país que más turistas registró; pero, a partir del 97 comenzó a decrecer el registro de turistas hasta llegar al nivel de Bolivia que es, de los cuatro países, el menos favorecido en actividad turística ${ }^{7}$.

Figura 2. Turistas en la Comunidad Andina por paises (1995-2005)

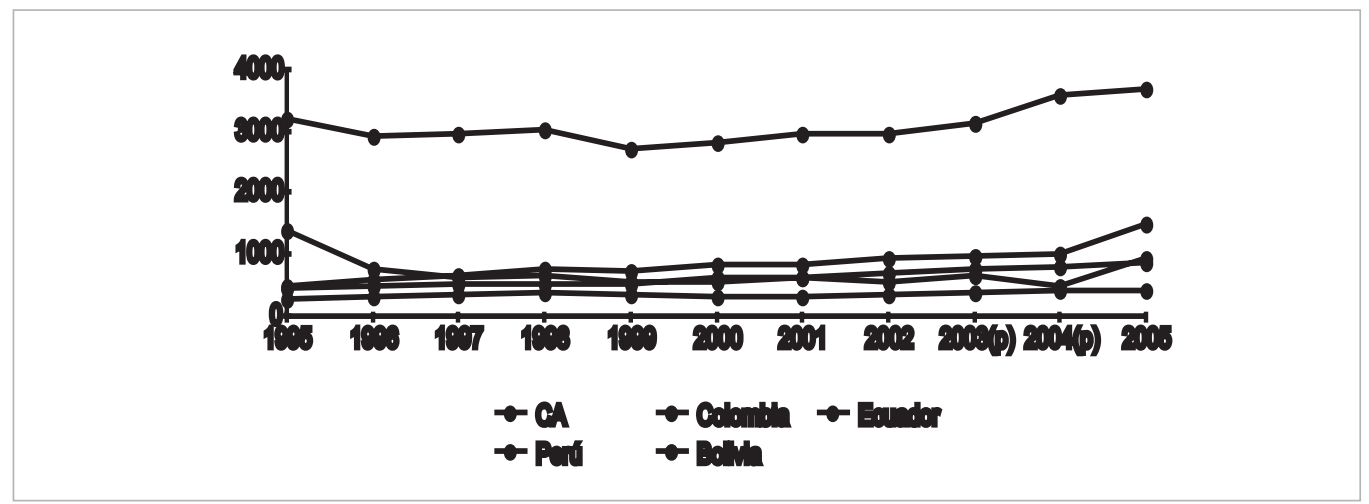

Fuente: Elaboración propia a partir de los datos proporcionados por la Comunidad Andina y la Organización Mundial de Turismo (2006).

6 Los datos estadísticos han sido extraídos de la página web: www.comunidadandina.org.

7 Se han extraído las cifras de Venezuela, a pesar de que en los años reflejados en la figura todavía pertenecía a la Comunidad. Las cifras de 2005 son provisionales y están proporcionadas por la OMT y la de 2005 de Bolivia por el comité de estadística de dicho país. 
Por último, cabe destacar el crecimiento leve, pero constante que ha experimentado Ecuador en los últimos diez años. Esto puede deberse al esfuerzo realizado por el país en cuanto a imagen de marca y promoción exterior, que hace que esté mejor posicionado que el resto, a pesar de la reciente dolarización de su economía.

\section{Crecimiento Turístico Vs Desarrollo Turístico en la CAN. Un reto para todos}

Desde el denominado «boom» de la actividad turística en la década de los sesenta-setenta, este sector ha adquirido una importancia creciente en los planes de desarrollo de regiones emergentes bajo la convicción de que se trata de un sector con un fuerte potencial para contribuir al crecimiento (Butler, 1980, Miosecc, 1977, Figuerola (1990), entre otros) y al desarrollo económico (Barbanza, 1970; Peck y Lepie, 1977-1989; Pearce, 1992 y Santana, 2003, etc.).

Las tasas de crecimiento de la CAN reflejan que existe aún un alto potencial de desarrollo de la actividad turística, la cual puede verse impulsada por las políticas de cada uno de los países por separado, así como por políticas comunes llevadas a cabo por la región o por el apoyo de organismos externos. A través de los diversos mecanismos de cooperación, se puede ofrecer una respuesta de carácter más general que no se limite únicamente a las actividades propias de la cooperación.

Sin embargo, a pesar de que el concepto de desarrollo turístico sostenible aparece en innumerables ocasiones en los principales documentos y acuerdos internacionales así como en múltiples publicaciones científicas (De Kadt, 1972; Krippendorf, 1982;; Mclntyre, Hetherington; Inskeep, 1991; Bramwell y Lane,
1993; Green, 1995; Hunter, 1995; Archer, 1996; Vera y otros, 2001; Burns, 2004; Ko, 2005, etc.), la realidad social de regiones como la CAN, se manifiesta muy distinta. La práctica impone numerosos condicionantes locales que impiden que puedan llevarse a cabo todas estas políticas.

En el caso de la Comunidad Andina, (aunque la integración está fortalecida) la situación particular de cada uno de sus integrantes no es tan robusta ${ }^{8}$. Individualmente cuentan con problemas político-sociales y altos niveles de pobreza que persisten con los años.

La cuestión de la pobreza y la desigual distribución de la riqueza en los cuatro países convierten a la CAN en la región con mayor nivel de desigualdad de América latina. Según los datos proporcionados por la Comisión Europea (2007), casi la mitad de la población andina vive en la pobreza,y casi una cuarta parte de la población pobre es de origen indígena.

En este sentido, parece que en la Comunidad Andina el crecimiento turístico no es sinónimo de desarrollo sostenible y equitativo para todos los agentes sociales. Se hace, por tanto, necesaria, una política turística enfocada al fortalecimiento de la sociedad civil a través de programas de capacitación y educación, financiación mediante microcréditos, etc. para que esta pueda participar de la actividad turística y beneficiarse de sus resultados.

Instituciones como la comisión Mundial del Medio Ambiente y del Desarrollo (Informe Brundtland, 1987) propone, en un catálogo de Requisitos para un desarrollo sostenible, la necesidad de contar con un sistema político que asegure la participación efectiva de los ciudadanos en la toma de decisiones.

8 Uno de los mayores retos de la integración regional de los países de la comunidad andina, lo ha protagonizado el abandono de Venezuela en 2006. La crisis provocada se superó cuando unos meses después los presidentes de Ecuador, Bolivia, Perú y Colombia se reunieron, afianzando la integración y proporcionándole una mayor confianza. 
En el año 2004, la CAN implementó el programa «Desarrollo con Inclusión Social» con el fin de lograr una mayor cohesión social, económica y territorial y en septiembre de 2004 aprobó el «Plan Integrado de Desarrollo Social» (PIDS) andino.

Este Plan pretendía reforzar la cohesión social regional a través de la coordinación y la participación de todas las administraciones pertinentes, con el fin último de terminar con la pobreza y la exclusión social.

Su aprobación es un primer paso para mejorar la gobernanza y promover un enfoque general de la cohesión social en el conjunto de la Comunidad Andina. Dentro de los planes del Plan se encuentran proyectos y programas enfocados al empleo, la salud, la educación y la cultura, el desarrollo rural y el medio ambiente. Promueve también una convergencia progresiva hacia metas y objetivos sociales acordados, que permitan cumplir los Objetivos de Desarrollo del Milenio.

Por otro lado, sumado al problema de la pobreza, se encuentran el del medioambiente y el de la gestión de los recursos naturales, que a su vez son la principal fuente de ingresos de la población rural. A esto se le añade la deficiente oferta de cobertura de servicios básicos, la falta de educación, el desempleo,... etc. Estos aspectos redundan en la falta de cohesión política en los países de la comunidad.

La mala praxis en la gestión de los recursos naturales ha llevado a una enorme devastación de biodiversidad, lo que además está provocando procesos de erosión acelerados, así como altos niveles de polución de los recursos hídricos y del suelo.

Por lo anterior, a la región andina, a pesar de contar con unos recursos naturales y culturales de alto valor, se le dificulta cada vez más convertir estos recursos en valor turístico. Esto obedece al mal estado y a la mala gestión de muchos de ellos, actualmente, así como a la falta de control, por parte de las autoridades competentes.

La deforestación, la contaminación en sus diferentes vertientes, el mal uso y gestión de los recursos debido, en la mayor parte de los casos, a falta de planificación, falta de control y ausencia de educación, son una limitación a una actividad que podría proporcionar una vía de salida a una de las regiones más pobres de América Latina.

El turismo puede ser una herramienta de cohesión social y desarrollo sostenible, si se gestiona cabalmente y se fomenta a través de los principios fundamentales de la gobernanza. La UE no puede perder esta oportunidad y ha de aprovechar este nuevo reto si desea contribuir al desarrollo de la Comunidad Andina y su sociedad.

\section{El camino hacia la gobernanza en turismo}

El término gobernanza se utiliza al hablar de los procesos de toma de decisión en los que se encuentran inmersos diferentes colectivos. La gobernanza es, según Stoker (1998), un proceso por el que el arte de gobernar depende de la colaboración entre un complejo entramado de jugadores procedentes de dentro y fuera del gobierno.

La gobernanza en turismo es un sistema de reglas formales e informales (normas, procedimientos, costumbres, etc.) que establecen las pautas de relaciones entre actores turísticos (considerando actores relevantes tanto a los poderes públicos como a la iniciativa privada y a los actores sociales).

Es conocido el proceso por el que determinados destinos en vías de desarrollo generan un movimiento que fuerza hacia la mejora en los 
procedimientos de desarrollo y la planificación de la actividad turística.

La modalidad de sol y playa, tan demandada en la década de los sesenta y setenta por los turistas occidentales, tuvo como consecuencia la implantación de un tipo de turismo que requería grandes espacios urbanizados e infraestructuras de alta inversión, difícilmente asumibles por la población local.

Por otro lado, los responsables públicos de estos destinos, cegados por los inminentes beneficios que producía este sector, no tuvieron en cuenta ningún tipo de proceso planificador que orientase y controlase los flujos turísticos internacionales y la entrada de grandes empresas extranjeras.

En la actualidad y, gracias al avance que se ha producido en torno a los procesos de desarrollo sostenible, una gran parte de estos destinos busca mecanismos de corrección de los impactos negativos de la actividad, así como instrumentos planificadores sostenibles.

No obstante, en varias ocasiones, las políticas de turismo, cuando se refieren al concepto de sostenibilidad, ahondan en cuestiones referentes al medio ambiente, dejando de lado los procesos de equidad en el reparto del beneficio, el empleo local, la inflación, el papel de la comunidad local y otros hechos de alta relevancia e impacto para los países en vías de desarrollo.

Por todo ello, en los últimos años se han ido incorporando a la temática turística y, más en concreto a los intentos de desarrollo turístico sostenible en el ámbito local, nuevos estilos de planificación, fruto de la evolución de la propia disciplina y de la adaptación a los nuevos contextos vigentes (OMT, 2001).

Se ha pasado de una situación en la que el Estado tenía la responsabilidad plena del bienestar público y las empresas incrementaban sus beneficios independientemente de los intereses de la sociedad en general, a un mundo en el que el éxito depende de la comunidad de intereses entre las empresas, la sociedad civil y los gobiemos (OMT, 2001), así como de organizaciones supranacionales como la Unión Europea.

La sociedad adquiere un papel de creciente importancia en la evaluación de la contribución de la industria turística al desarrollo y al bienestar de la comunidad local, recompensando aquellos comportamientos que benefician a ésta y penalizando a los que no lo hacen. Así mismo, se encuentra en un momento en el que desea participar en las decisiones que le afectan y, por tanto, tomar partido de los asuntos que pueden repercutir en su destino ${ }^{9}$.

El Estado tiene que reinventarse y enfocar su papel desde un punto de vista más estratégico, sustituyendo sus actuaciones tradicionales por otras que fomenten la creación de capital social y de confianza entre los agentes del sistema turístico ${ }^{10}$.

De este modo, el desarrollo turístico sostenible local se potencia a través de la participación, adoptando fórmulas como el autodiagnóstico participativo ${ }^{11} \mathrm{y}$, más adelante, la autogestión

9 El 3 de marzo de 2005 tuvo lugar el Primer Foro de la Sociedad Civil en relaciones UE-CAN. El principal objetivo de este foro fue el de compartir experiencias en lo que se refiere a las relaciones de la UE con la Comunidad Andina, haciéndose especial hincapié en el tema de la cohesión social para la reducción de la pobreza.

10 El Estado ha de seguir los principios fundamentales que marcan las nuevas teorías de la gobernanza.

11 Método de investigación que involucra a la comunidad residente con responsabilidad en la búsqueda y definición del perfil o modelo de destino turístico que desean. 
o gestión participativa ${ }^{12}$. El objetivo es establecer que las decisiones que afectan a la comunidad se tomen entre todos los miembros de la misma y no sólo entre unos pocos.

En la mayor parte de los destinos turísticos de América Latina (y en casi todos los países del mundo) las decisiones en materia turística las toman las administraciones públicas unilateralmente o en conjunto con los representantes de las más importantes empresas privadas del sector. Esta situación provoca que el desarrollo turístico que resulta no atienda a los intereses de una gran parte de la población local, la cual permanece insatisfecha ${ }^{13}$.

Uno de los aspectos más relevantes es el de la organización, en forma de red, de las comunidades locales, nacionales o regionales; un sistema turístico en red donde participen distintos grupos sociales y económicos y donde los procesos de interacción y colaboración se conviertan en las herramientas básicas para el desarrollo turístico.

La mayor parte de los países en vías de desarrollo cuentan con marcos institucionales muy débiles lo que implica que no existe confianza entre los agentes y, por tanto, la colaboración se hace muy difícil.

De este modo, las organizaciones nacionales y supranacionales deben tratar de fomentar o formalizar cauces que contribuyan a fortalecer estas conexiones, entre actores involucrados en la actividad turística, si lo que se desea es apoyar un desarrollo integral y sostenible a través de este sector. De nada servirán proyectos turísticos financiados por instituciones en países o regiones donde no se construyan redes de colaboración.
El flujo turístico que se genere beneficiará a una pequeña parte de la sociedad, pero nunca logrará solventar aspectos como la pobreza o la exclusión social.

En el marco de estas iniciativas, la Organización Mundial de Turismo de las Naciones Unidas (UN.WTO) es pionera en la creación del programa UN.WTO «TedQual Volunteers», cuyo objetivo es proveer a países en vías de desarrollo de un equipo de expertos planificadores de la UNWTO, junto con jóvenes voluntarios posgraduados en turismo, para desarrollar proyectos de desarrollo turístico sostenible en áreas o destinos con alta potencialidad.

El principio fundamental que marca este programa es el de la gobernanza para el desarrollo turístico sostenible; la Organización Mundial de Turismo tiene como premisa el fomento de redes locales de agentes turísticos a través de la actividad turística.

Los beneficios de este programa redundan en todos los participantes:. el país de acogida obtiene un trabajo de consultoría de alto nivel por un bajo coste, donde se involucran todos los agentes de la actividad turística; los voluntarios participantes obtienen formación a través de una experiencia real de desarrollo turístico y las universidades involucradas generan conocimiento.

En la región andina, hasta el momento, se han realizado dos proyectos de este tipo. El primero de ellos en la Región Interandina del Ecuador, donde se involucró a la población local, a las distintas administraciones públicas y al sector privado de la zona. El segundo, se llevó a cabo en Armenia (Colombia) y el resultado final fue un Plan de Competitividad para el destino.

\footnotetext{
12 Participación comunitaria en los procesos de toma de decisiones del destino.

${ }^{13}$ Uno de los retos que la Unión Europea, en sus políticas de cooperación, habrá de atender es el control y el establecimiento de una premisa imprescindible respectos de quiénes van a gestionar, en último término, la financiación concedida. Así mismo, sería muy interesante el que, en todos los programas para su concesión, se solicitase un acuerdo previo entre los distintos actores sociales.
} 
En definitiva, uno de los retos para la Unión Europea en el establecimientos de relaciones en materia de desarrollo turístico con la Comunidad Andina, es el apoyo a esta región a través de programas que tengan como objetivo conseguir un funcionamiento eficaz de redes más o menos institucionalizadas de actores turísticos estratégicos que dispongan de cauces de participación y de su propia autonomía en los procesos de toma de decisiones.

\section{NUEVOS RETOS PARA LA COOPERACIÓN AL DESARROLlO UE -COMUNIDAD ANDINA. DEL DESARROLLO TURÍSTICO SOSTENIBLE A LA COHESIÓN SOCIAL}

Papel de la Unión Europea en materia de Política de Cooperación al Desarrollo respecto de la Comunidad Andina.

Las acciones de cooperación de la comunidad europea con la comunidad andina comenzaron en los años setenta y estuvieron principalmente enfocadas al apoyo en el proceso de integración y a determinadas políticas sectoriales.

Si bien, durante mucho tiempo distintos círculos han criticado que en la década de los noventa la Comunidad Andina quedó significativamente marginada del proceso de negociación de nuevos acuerdos internacionales por parte de la Unión Europea, las razones pudieron venir de las inestabilidades políticas de los países ${ }^{14}$.

Lo cierto es que la cooperación andino-europea ha evolucionado con el tiempo. En la década de los setenta, estaba fundamentada en lo económico y comercial; en los años ochenta se hizo especial hincapié en la cooperación para el desarrollo y en los noventa, se ahondó en la cooperación industrial y científico tecnológica ${ }^{15}$.

Algunas de estas políticas fueron las relacionadas con materias energéticas y medioambientales y perseguían principalmente aprovechar el conocimiento existente sobre estos ámbitos en Europa y establecer dinámicas de cooperación entre los países de la Comunidad andina para favorecer el proceso de integración.

La Comunidad Andina y la Unión Europea suscribieron en Roma, el 30 de junio de 1996 una Declaración Conjunta sobre el Diálogo Político, creando un marco institucional a un diálogo que mantenían de manera informal. El Acuerdo Marco de Cooperación CAN-UE, fue suscrito en 1992 y constituye la base jurídica de la cooperación de la Unión Europea administrada por la Comisión Europea.

Fue durante la II Cumbre de Jefes de Estado y de Gobierno de América Latina, Caribe y la

\footnotetext{
14 De las pocas iniciativas fue la creación de un esquema específico para el ámbito de las drogas en el año 1990.

15 El siglo XXI debe, por tanto, dar paso a una cooperación basada en el fortalecimiento de las capacidades institucionales en el marco del fomento de los principios básicos de la gobernanza.
} 
Unión Europea, realizada en Madrid (2002), cuando la CAN y la UE, en el marco de una reunión de Jefes de Estado, decidieron negociar un Acuerdo de Diálogo Político y de Cooperación como paso previo al inicio de las negociaciones para un Acuerdo de Asociación entre ambos bloques. Este fue suscrito en Roma el 15 de diciembre de 2003, en el marco del Consejo Europeo.

En la III Cumbre ALC - UE, celebrada en Guadalajara (2004), se dio un mayor impulso al diálogo entre regiones y se trabajó de manera muy especial el tema de la cohesión social.

Los último acontecimientos relevantes respecto de las relaciones entre la unión Europea y la Comunidad andina han venido marcados por El Consenso europeo sobre Desarrollo (2006); esto es, una declaración conjunta del Consejo y de los Representantes de los Gobiernos de los Estados miembros reunidos en el seno del Consejo, del Parlamento Europeo y de la Comisión sobre la política de desarrollo de la Unión Europea.

Uno de los aspectos más interesantes, respecto del ámbito del establecimiento de cauces de colaboración y cooperación entre agentes, es el epígrafe dedicado a principios comunes de todos los Estados Miembros en el que se destaca el de la participación de la sociedad civil. En él, se hace especial hincapié en la necesidad de que la UE propugne una amplia participación de todos los interlocutores interesados en el desarrollo de los países y aliente la participación de todos los sectores de la sociedad. La sociedad civil, de la que forman parte los interlocutores económicos y sociales -como los sindicatos, las organizaciones de empresarios y el sector privado-, las ONG y otros agentes no estatales de los países asociados, en particular, desempeñan un papel esencial como promotores de la democracia, la justicia social y los derechos humanos.

De este modo, la UE se compromete, en esos nuevos retos que asumirá en el siglo $\mathrm{XXI}$, a intensificar su apoyo a la creación de capacidades de los agentes no estatales con el fin de fortalecer su voz en el proceso de desarrollo y hacer avanzar el diálogo político, social y económico.

Por otro lado, cabe destacar la Declaración de Viena (2006) que tuvo lugar en el marco de la Cuarta Cumbre Unión Europea-Amércica Latina y Caribe, en la que los Jefes de Estado y de Gobierno de la Unión Europea y deAmérica Latina y el Caribe reiteraron su compromiso para seguir promoviendo y reforzando la asociación estratégica birregional, acordada en las cumbres anteriores

Desde los inicios en materia de cooperación entre la Comunidad Europea y la Andina se ha ido avanzando, hasta que en el 2002 se aprobó la Primera Estrategia Regional para la Comunidad Andina (2002 - 2006) ${ }^{16}$, cuyos objetivos eran, por un lado, seguir potenciando la integración de la región y por otro, fomentar una región de paz, a través del diálogo político.

Dentro de esta estrategia de cuatro años, se han realizado proyectos de prevención de catástrofes ${ }^{17}$; la armonización de los sistemas de estadísticas de los países de la Comunidad Andina ${ }^{18}$; asistencia técnica para consolidar y

\footnotetext{
${ }^{16}$ Según los datos proporcionados por la Comisión Europea (2007), la estrategia regional para la Comunidad Andina durante el periodo 2002-2006 contaba con una dotación financiera para la cooperación de unos 29 millones de euros.

17 El objetivo de este proyecto es fomentar la coordinación y estimular el intercambio de experiencias entre las distintas instituciones y organizaciones nacionales encargadas de la prevención de catástrofes (contribución de la CE, 9,45 millones de euros).

18 Contribución de la CE, 5 millones de euros.
} 
reforzar el proceso de integración económica de la región para la creación de un mercado común en la zona ${ }^{19}$; incremento de la participación de la sociedad civil en la integración de la región andina ${ }^{20}$ y freno al problema ocasionado por el aumento de las drogas sintéticas ${ }^{21}$

El balance realizado por la Comisión Europea de este programa (2002-2006) arroja que la implementación de los proyectos se está acelerando, aunque el comienzo haya sido lento. Esta aceleración se produce, a pesar de las dificultades y limitaciones impuestas por los cambios políticos de los distintos países y la limitación de los recursos humanos de la Secretaría General de la CAN, (principal responsable de la implementación de los proyectos regionales),... Para superar estas barreras, la Comisión concluye, que la Comunidad Andina ha de mejorar la asunción de los proyectos.

Además de los proyectos de cooperación que se llevan a cabo desde la Comisión Europea, existen otros proyectos ejecutados por países miembros que se han solapado con los proyectos regionales.

Dentro de los países que han realizado proyectos de este tipo están Francia, Alemania, Reino Unido y Suecia. Además de estos, España ha mostrado interés por cooperar con la Comunidad Andina en aspectos como la cohesión social, el gobierno democrático, desarrollo territorial y protección del medioambiente. En temas ambientales se destacan las acciones de Finlandia, que está apostando por incrementar el conocimiento y el desarrollo sostenible del Amazonas.

Otros organismos que tienen a cargo acciones de cooperación son el Banco Interamericano de
Desarrollo y la Corporación Andina de Fomento (CAF). Esta cantidad de agentes involucrados en los proyectos de cooperación con la comunidad, requiere de la existencia de coordinación e información fluida entre los participantes para evitar duplicidades y generar sinergias en cada una de las acciones que se llevan a cabo.

Una vez alcanzado el fin de la Primera Estrategia 2002 - 2006, se ha aprobado una Segunda Estrategia 2007-201322, que se centra en tres pilares básicos: reforzar la integración económica, apoyar iniciativas para la cohesión social y económica y colaborar en la lucha contra la droga.

El contexto de esta estrategia es la Declaración sobre la Política de Desarrollo de la Unión Europea de diciembre de 2005, que tiene como principal objetivo la cooperación para el desarrollo de la Unión Europea a través de la erradicación de la pobreza mediante el desarrollo sostenible, incluyendo el cumplimiento de los objetivos de Desarrollo del Milenio.

Según la propia Comisión Europea, uno de los mayores riesgos de la Estrategia 2007 2013 es el bajo nivel de compromiso de los cuatro países de la región en el proceso de integración regional, que a su vez trae como consecuencia la falta de recursos financieros para continuar el proyecto. Esto puede generar, a su vez, un cierto nivel de indiferencia respecto a los proyectos de la región.

Para evitar, en la medida de lo posible, esta situación se debería garantizar la asunción de los proyectos por parte de cada país y

\footnotetext{
19 Contribución de la CE, 8 millones de euros.

20 Contribución de la CE, 4,1 millones de euros.

21 Contribucion de la CE, 2,55 millones de euros.

Documento de la Comisión Europa «comunidad Andina. Documento de Estrategia Regional. $2007-$ $2013 » 12.04 .2007$ (E/2007/678).
} 
una mayor implicación de los agentes a los que van dirigidos dichos proyectos. También se deberían considerar las diferencias existentes entre los cuatro países en aspectos relacionales con el desarrollo de sus economías, de modo que los diferentes proyectos se adapten a las diferencias de cada uno.

Desde la Comisión Europea se plantea como alternativa para superar estas limitaciones, que se trabaje desde el Plan Integrado de Desarrollo Social aprobado por los Ministros de Asuntos Exteriores de los países de la CAN; de esta manera, las iniciativas garantizarán la plena asunción de los proyectos y habrá una mayor visibilidad de la CAN como ente regional y de la UE como su principal donante.

\section{Un nuevo desafío para la UE en su política de cooperación con la Comunidad Andina. Del desarrollo turístico a la cohesión social a través de la gobernanza}

Si bien las normas y procedimientos democráticos se han ido extendiendo a lo largo de América Latina, la gobernanza democrática para Rodríguez y Winchester (1997), está lejos de ser consolidada y, como en muchos países, ni siquiera muestra tendencia a fortalecerse.

Por consenso general, las formas de gobierno en América Latina se consideran sobrecentralizadas y con alta concentración del poder; históricamente y, en muchos casos, aun hoy, las élites tradicionales han utilizado el poder judicial, legislativo y gubernamental para controlar las decisiones de política pública y para bloquear el ejercicio de la mayoría de los derechos ciudadanos básicos, especialmente el derecho a organizarse y a defender sus propios intereses. Sin embargo, paralelamente a esta concentración del poder o quizás debido a ella, también ha crecido la necesidad y demanda por nuevas y más democráticas formas de gobernanza (Whittingham, 2002).

Respecto de la Unión Europea, su interés por la gobernanza tiene como una de sus expresiones el Libro Blanco de la Gobernanza Europea (2001), que analiza la manera en que la Unión utiliza los poderes que le otorgan sus ciudadanos y explica las razones por las que los principios por los que se rigen sus instituciones han de ir trasformándose hacia los que señala lagobernanza.

En este sentido, el Libro Blanco propuso abrir el proceso de elaboración de las políticas de la UE con el fin de asociar a un mayor número de personas y organizaciones en su formulación y aplicación, lo que se traducirá en una mayor transparencia y en una mayor cesión de responsabilidades para todos los participantes.

Asimismo, la Comisión Europea publica en el año 2003 un informe sobre la Gobernanza Europea que tiene como objetivo extraer las lecciones aprendidas del Libro Blanco y, al mismo tiempo, analizar cuál debería ser la aplicación práctica de los postulados defendidos en el citado Libro.

Respecto al ámbito de la gobernanza mundial, el propósito desde la Unión Europea es el de tratar de aplicar los principios de buena gobernanza a todas sus responsabilidades mundiales. Así, en el largo plazo, se haría lo posible por aumentar la eficacia y las competencias de ejecución de las Instituciones internacionales. En el corto plazo, sin embargo, tendrán que aumentar las asociaciones con otros países, con el fin de promover una mayor cooperación y coherencia entre las actividades de las organizaciones internacionales existentes, incrementando, además, su transparencia. 
Al aplicar los principios de la buena gobernanza a sus responsabilidades con la CAN, la Unión debería practicar una mayor apertura ante los agentes turísticos gubernamentales y no gubernamentales de los países ${ }^{23}$. Este enfoque habría de complementarse con la necesidad de que los citados agentes adquieran el compromiso de asumir una serie de responsabilidades en materias relativas a la cooperación y colaboración para el desarrollo turístico sostenible y la consecuente cohesión local ${ }^{24}$.

La propia Unión Europea destaca, cuando define sus relaciones con la CAN en materia de cohesión social, la necesidad de participación de los ciudadanos en los procesos de toma de decisiones mediante la consulta de las organizaciones de la sociedad civil.

La UE ha de sumarse a iniciativas en el marco de un plan de desarrollo e inclusión social, pero en el ámbito del desarrollo turístico. Un proceso de sensibilización en el que se comience a detectar a la actividad turística como uno de los instrumentos más importantes para favorecer la cohesión social, haciendo partícipes a todos los agentes.

Si bien, dentro de los objetivos de las relaciones de la Unión Europea con la Comunidad Andina están la reducción de las desigualdades sociales, la lucha contra la pobreza, la buena gobernanza, el Estado de Derecho, la justicia, el desarrollo sostenible, el desarrollo institucional y la cohesión social, entre otros, la realidad es que los programas de turismo suelen encuadrarse dentro de programas económicos o ambientales y muy pocas veces el reto fundamental de un proyecto de desarrollo turístico tiene como objetivo el área social.

Por otro lado, el decrecimiento manifiesto en el volumen de turismo emisor de la CAN evidencia que la calidad de vida de la población ha bajado en los últimos años $y$, por ello, los ciudadanos no tienen recursos para poder disfrutar del turismo fuera de su país. El turismo social, que así se denomina a la modalidad de turismo que tiene por objeto hacer que toda la sociedad, sin excepción, pueda tener acceso al disfrute de unas vacaciones, es un tema que la UE debería tratar de potenciar también en sus políticas de cooperación, a través de proyectos enmarcados en aspectos tales como la reducción de la desigualdad social.

Sin embargo, se hace fundamental tener en cuenta varios aspectos que podrían limitar los resultados de programas de cooperación en materia turística financiados por la UE en la CAN.

En este sentido, un destino turístico que recibe una ayuda financiera directa o indirecta de la UE podría hacer que los actores cooperasen para gestionar la citada ayuda o asignación financiera. Sin embargo, en este caso, la cooperación nace de una oportunidad coyuntural, generalmente limitada en el tiempo y sigue la meta del proyecto; por tanto, su lógica es meramente técnico-económica.

${ }^{23}$ En la mayor parte de las ocasiones no se tienen en consideración como agentes turísticos a individuos u organizaciones de la sociedad civil que, si bien, no se encuentran inmersos en la actividad sí se ven directamente repercutidos por la misma. Esta labor de identificación de actores relevantes sería una responsabilidad importante para la UE si desea que sus programas actúen sobre todas las partes implicadas.

De forma poco visible, la Comisión está desarrollando su diálogo con actores gubernamentales y no gubernamentales de terceros países sobre el uso de nuevos instrumentos en el mundo, como complemento del Derecho internacional vinculante y la promoción del debate sobre la manera en que la UE puede contribuir a una reforma general de las instituciones multilaterales. De esta manera, está estableciendo progresivamente las bases para futuros progresos de los mecanismos y de la cooperación sobre gobernanza mundial (Comisión Europea, 2003). 
En estas situaciones, es muy complicado asegurar que el proceso relacional genere el suficiente desarrollo turístico como para fomentar la equidad y la cohesión social.

Por ello, la cooperación para el desarrollo de la UE en la CAN ha de asegurar, a través de mecanismos de control y planteamientos previos de gobernanza, que los programas provoquen una experiencia positiva para todos los actores de manera que, tras su finalización, los grupos de interés continúen aplicando mecanismos de colaboración. Esto es, que las extenalidades que la situación de trabajo cooperativo han producido, impulsen a los agentes a provocar relaciones continuadas en el tiempo.

En otras ocasiones, los procesos de colaboración turística en destinos de la CAN podrían comenzar como mecanismo de desarrollo al servicio de una estrategia local a largo plazo de la propia región. En este caso, la UE debería apoyar estos procesos iniciados, identificar a los agentes involucrados, definir las interrelaciones que se están produciendo entre ellos y evaluar los resultados en el marco del desarrollo sostenible.

Únicamente con este análisis podrán comenzar a definirse programas de actuación concretos para la zona. Es importante evitar generar proyectos que no se adecuen a las necesidades o donde no se incorporen a todos los grupos relacionados.

En este sentido, se ha de potenciar la participación de los agentes públicos, privados y de la sociedad civil en la elaboración de propuestas para la UE o en la creación de plataformas de debate más amplias y eficientes.

En la segunda de las opciones, los destinos de la CAN se apoyan en una estrategia que requiere tiempo y cuya finalidad es concienciar a todos los agentes, modificar sus comportamientos y lograr el compromiso responsable del mayor número de grupos de interés posible. En este caso, el proceso de colaboración entre agentes surge en el momento en el que algún grupo de actores tiene el deseo de asociarse con otro $u$ otros elementos del sistema turístico y no cuando recibe la ayuda financiera.

Otro de los puntos que la UE habría de tener en cuenta es la necesidad de detectar grupos de la sociedad civil que deseen intervenir de manera activa en la realidad económica, social y cultural, fruto de la actividad turística de un destino.

En el Acuerdo Político de cooperación UE-CAN suscrito en Roma, se reconoce la contribución potencial de la sociedad civil en el proceso de cooperación y se acuerda promover un diálogo efectivo con ésta; sin embargo, no institucionaliza ningún mecanismo concreto y efectivo, dejándolo en manos de los Estados Miembros. Son las instituciones públicas las responsables de promover la colaboración entre agentes del sector turístico a través de mecanismos formales o informales.

Así , la UE ha de atender las peticiones realizadas en el Primer Foro de la Sociedad Civil sobre las Relaciones UE-CAN (2005), donde se reclama la necesidad, para las organizaciones de la sociedad civil, de incrementar las opciones de ser consultadas y de participar de manera efectiva en los diferentes acuerdos entre regiones, así como en las políticas de cooperación y desarrollo.

Si no existiesen las citadas organizaciones de la sociedad civil interesadas por el turismo como mecanismo de desarrollo, la UE habría de concienciar, a través de diversos programas de educación, formación y capacitación, sobre las ventajas de la actividad y la necesaria participación de estos grupos sociales para que efectivamente sirvan como instrumento de reducción de la pobreza.

En este sentido, es muy importante tener en cuenta los aspectos sociales y políticos que se desarrollan en el marco de la economía de un destino turístico. Por ello, se hace prioritario que la UE fomente que los agentes cooperen y 
colaboren más de lo que las asunciones de racionalidad económica e individual implicarían. En ocasiones parece que el instrumento de Cooperación al desarrollo está subsumido al de Cooperación Económica y la UE ha de separarse de la citada presunción.

Políticas de fortalecimiento del marco institucional y de la confianza entre los distintos actores turísticos de los destinos de la CAN harían que surgiese uno de los primeros gérmenes necesarios en cualquier proceso de cooperación. Esta área podría trabajarse a la luz de la experiencia europea de construcción de una base de reglas del juego regionales, teniendo en cuenta las especificidades locales y nacionales.

Respecto de esto último, existe una clara distinción entre tipologías de colaboración entre agentes. Según Adler y Kwon (2002), los acuerdos entre grupos de interés pueden estar fundamentados en tres elementos distintos: el económico, el jerárquico y la confianza. El primero hace que la cooperación se desarrolle entre empresas turísticas (relaciones de mercado); el segundo tiene connotaciones de mandato y control y el último, el denominado acuerdo orgánico, tiene como fundamento la verdadera conciencia de obtener beneficios mutuos sobre la base de la confianza ${ }^{25}$. Este sería el tipo de interrelaciones que habrían de fomentarse en un destino turístico y la UE, respecto de la CAN, tiene una oportunidad de poder contribuir a ello.

Sin embargo, las políticas de cooperación UECAN deben ser conscientes de que, en ocasiones, las interrelaciones entre agentes turísticos también pueden producir efectos negativos. En algunas oportunidades, los acuerdos de colaboración se llevan a cabo entre una parte exclusiva de grupos de interés del destino; unas minorías con el suficiente poder como para tomar decisiones que afecten al resto e incluso que les perjudiquen. Por ello, se hace prioritario que, en el marco de las relaciones UECAN se establezcan unas normas o reglas del juego claras y equitativas para toda la sociedad local, en referencia a la actividad turística.

Es de vital importancia que los programas de cooperación al desarrollo y el conjunto de relaciones que la UE mantiene con la CAN tengan en cuenta las especificidades del desarrollo turístico en esta región y eviten la promoción de soluciones asistencialistas a favor de proyectos estratégicos de largo plazo.

La UE ha de tratar de compatibilizar todas sus actuaciones en materia de cooperación al desarrollo en la CAN, con las que llevan a cabo el resto de Estados Miembros así como con los programas que la propia CAN y sus países gestionan en su región. De este modo, se evitarán duplicidades y se seguirán los mismos principios fundamentales que permiten que el desarrollo turístico contribuya a la cohesión social, a través de fórmulas de cooperación, basadas en los principios de la gobernanza.

En definitiva, la política de cooperación al desarrollo de la UE, en el marco de sus relaciones con la CAN, tiene la oportunidad de utilizar al turismo como motor de desarrollo económico y social. Sin embargo, los programas que se lleven a cabo habrán de tener en cuenta los principios de la gobernanza que señalan la necesidad de hacer partícipes a todos los actores sociales ${ }^{26}$.

\footnotetext{
25 Todos aquellos acuerdos que no estando dentro de la pura relación de mercado ni respondiendo a situaciones de dependencia jerárquica se producen entre agentes turísticos con el objetivo de mejorar sus posibilidades de acceso a determinados recursos, reducir costes de transacción o simplemente aprovecharse de resultados fruto de la sinergia.

26 Resultará sorprendente para muchos lectores, que este artículo haga un hincapié tan especial en la gobernanza para el desarrollo turístico en las relaciones externas de la UE con otra región, pues, la realidad es que la propia Unión Europea no ha concedido la relevancia que se merece a la actividad turística en su propio territorio, dejándola, en muchas ocasiones, relegada a un plano secundario. Cabría preguntarse, ¿cuál es la actual política turística europea?. Muchos autores e investigadores tendrían serias dudas para contestarla.
} 


\section{ConCLUSIONES}

Tras el análisis de la potencialidad turística de la Comunidad Andina, así como la evolución de las relaciones de la Unión Europea con la CAN, se concluye que para que el apoyo de la UE en el ámbito del turismo responda a criterios de gobernanza para el desarrollo sostenible, algunas de las actuaciones que la Unión ha de fortalecer, vienen delimitadas por los recomendaciones que siguen a continuación:

- Generar una plataforma permanente para el diálogo y la consulta de organizaciones de la sociedad civil interesadas por el desarrollo turístico de la CAN. De este modo, la UE estará siguiendo los principios fundamentales que se propone en sus políticas para la cohesión social.

- Proporcionar una mayor apertura a la participación de todos los agentes turísticos en el planteamiento de las políticas de cooperación al desarrollo de la UE con la CAN.

- Promocionar programas de sensibilización hacia las instituciones de la UE, los ciudadanos y expertos europeos y los Estados Miembros para incluir el desarrollo turístico dentro de los planes de desarrollo social que se llevan a cabo en el ámbito de la cooperación.

- Crear proyectos específicos de turismo social en la Comunidad Andina para mejorar la calidad de vida de los ciudadanos.

- Propiciar la implantación de mecanismos de control en los programas de desarrollo turístico para asegurar que los diferentes grupos de interés continúan aplicando las actuaciones y principios que se marcaron en un momento inicial (principios basados en la gobernanza).
- Apoyar de manera especial aquellas iniciativas de cooperación y colaboración en el marco del desarrollo turístico que surjan de parte de algún agente de la CAN. En este sentido, se tendrán que identificar los actores involucrados y definir las relaciones que mantienen unos con otros.

- Compatibilizar las acciones de cooperación al desarrollo en la CAN con los Estados Miembros, así como con las iniciativas de la propia CAN y sus países.

- Concienciar, a través de programas de educación, formación y capacitación a todos los actores sociales involucrados en el sector turístico de la CAN, acerca de las ventajas de la actividad y de la necesaria cooperación de estos grupos para que el turismo resulte un instrumento al servicio del desarrollo.

- Ampliar significativamente las relaciones UECAN, enfatizando en el hecho de que los agentes turísticos cooperen más allá de las meras relaciones económicas. Para ello, el desarrollo turístico ha de introducirse en programas como la cohesión social.

- Proyectar políticas de fortalecimiento del marco institucional de las distintas regiones de la CAN, así como de mejora de la confianza entre los distintos actores de la actividad turística.

- Utilizar los modelos de desarrollo turístico europeos para que las distintas experiencias (positivas y negativas) sirvan a la UE en sus políticas de cooperación con la CAN. 


\section{Bibliografía}

- ADLER, P. Y KWON S. 2002). Social Capital: Prospects for a new concept. Academy of Management Review. Vol. 27, n1, págs. 27 - 40.

- ARCHER, B. (1996). «Sustainable tourism - Do economists really care? Progress in Tourism and Hospitalityt Research, Vol. 2, № 3-4, págs. 217-222.

- BARBAZA, Y. (1970). «Trois types d'intervention du Tourisme dans l'organisation de l'espace littoral». Annales de Géographie n 434, págs.446-449.

- BRAMWELL, B Y LANE, B. (1993). «Sustainable tourism: an evolving global approach». Journal of Sustainable Tourim, $n^{\circ} 1$ (1), págs. 6-16.

- BUTLER, R.W.(1980). «The Concept of a Tourist Area Cycle of Evolution: Implications for Management of Resources». Canadian Geographers, Vol. 24, págs.5-12.

- BURNS, P. (1999). «Paradoxes in Planning: Tourism Elitism or Brutalism?». Annals of Tourism Research, vol. 26, págs. 329-348.

- COMISIÓN DE LAS COMUNIDADES EUROPEAS (2007). «Comunidad Andina. Documento de Estrategia Regional. 2007 - 2013. «12.04.2007 (E/2007/678).

- COMISIÓN DE LAS COMUNIDADES EUROPEAS (2003). «Informe de la Comisión sobre la Gobernanza Europea». Luxemburgo: Oficina de Publicaciones Oficiales de las Comunidades Europeas.

- COMISIÓN DE LAS COMUNIDADES EUROPEAS (2001). «La Gobernanza Europea. Un Libro Blanco». Bruselas. COM (2001) 428 final.

- DE KADT, E. (1992). «Making the Alternative Sustainable: Lessons from Development for Tourism». In Tourism Alternatives: Potentials and Problems in the Development of Tourism, V. Smith and W. Eadington, eds., pág. 47-75. Philadelphia: University of Pennsylvania Press.

- FIGUEROLA, M. (1990). Teoría Económica del Turismo. Ed. Alianza Universal Textos. Madrid.

- GREEN, H. (1995). Planning for sustainable toruism development. Inc. Hunter y Green Eds. Tourism and Environment. Pp. 93-121. London, Routledge.

- GRUPO SUR EUROPEO (2005). «Cuatro Claves para el Establecimiento de una Zona Andina de Paz. I Foro de la Sociedad Civil sobre las Relaciones UE - CAN. 
- HUNTER, C. (1995). «On the need to re-conceptualise sustainable tourism development. « Journal of Sustainable Tourism. 3 (3), págs. 155-165.

- INSKEEP, E. (1991). Tourism planning: An integrated and sustainable development approach. Van Nostrand Reinhold. New York.

- KO, T.G. (2005). «Assesing progress of tourism sustainability. Annals of Toruism Research. $^{\circ} 28$ (3), págs. 817-820.

- KRIPPENDORF, J. (1982). «Towards New Tourism Policies: The Importance of Eviromental and Socio-cultural Factors». Tourism Management.Vol. 3, págs. 135-148.

- MCINTYRE, G., HETHERINGTON, A., INSKEEP, A. (1993). Sustainable Tourism Development: a Guide for Planners. WTO. Madrid.

- MIOSSEC, J.M. (1976). Elements pour une Theorie de l'Espace Touristique. Les Cahiers du Tourisme, C-36 CHET,Aix-en-Provence: CHET.

- OMT (2001). Cooperación entre los Sectores Público y Privado. Para una Mayor Competitividad del Turismo. Madrid.

- OMT (2006). Tourism Highlights. Edition 2006. Organización Mundial de Turismo. Madrid.

- PEARCE, D.G. (1992). Tourist Organizations. Routledge.

- PECK, J.G. y LEPIE, A. (1992) [1977; 1989]. «Turismo y desarrollo en tres enclaves costeros de Carolina del Norte». En Smith, V.L. (ed.), Anfitriones e invitados, págs. 303-333. Madrid: Endymion.

- PLAN INTEGRADO DE DESARROLLO SOCIAL (2004). Reunion extraordinaria del consejo andino de ministros de relaciones exteriores. Decisión 601. 21 de setiembre de 2004. Nueva York - Estados Unidos de América.

- RODRÍGUEZ, A. \& WINCHESTER, L. (ed.) Ciudades y Gobernabilidad en América Latina, Santiago de Chile: Ediciones SUR, 1997.

- SANTANA, M. (2003). Formas de desarrollo turístico, redes y situación de empleo. El caso de Maspalomas (Gran Canaria). Tesis doctoral. Departamento de Sociología. Universidad Autónoma de Barcelona.

- SELIN, S. y CHAVEZ, D. (1995). «Developing an Evolutionary Tourism Partnership Model». Annals of Tourism Research. Vol. 22, n 4, págs.844-856. 
- STOKER (1998). "Governance as theory: five propositions». International Social Science Journal.

- VERA REBOLLO, J.F. y otros (2001). «Planificación y Gestión del Desarrollo Turístico Sostenible: Propuestas para la Creación de un sistema de Indicadores». Instituto Universitario de Geografía. Universidad de Alicante. №. 1, págs. 1-75.

- WHITTINGHAM M. V. (2002). «Aportes de la teoría y la praxis para la nueva gobernanza». VII Congreso Internacional del CLAD sobre la Reforma del Estado y de la Administración Pública, Lisboa, Portugal, 8-11 Oct. 


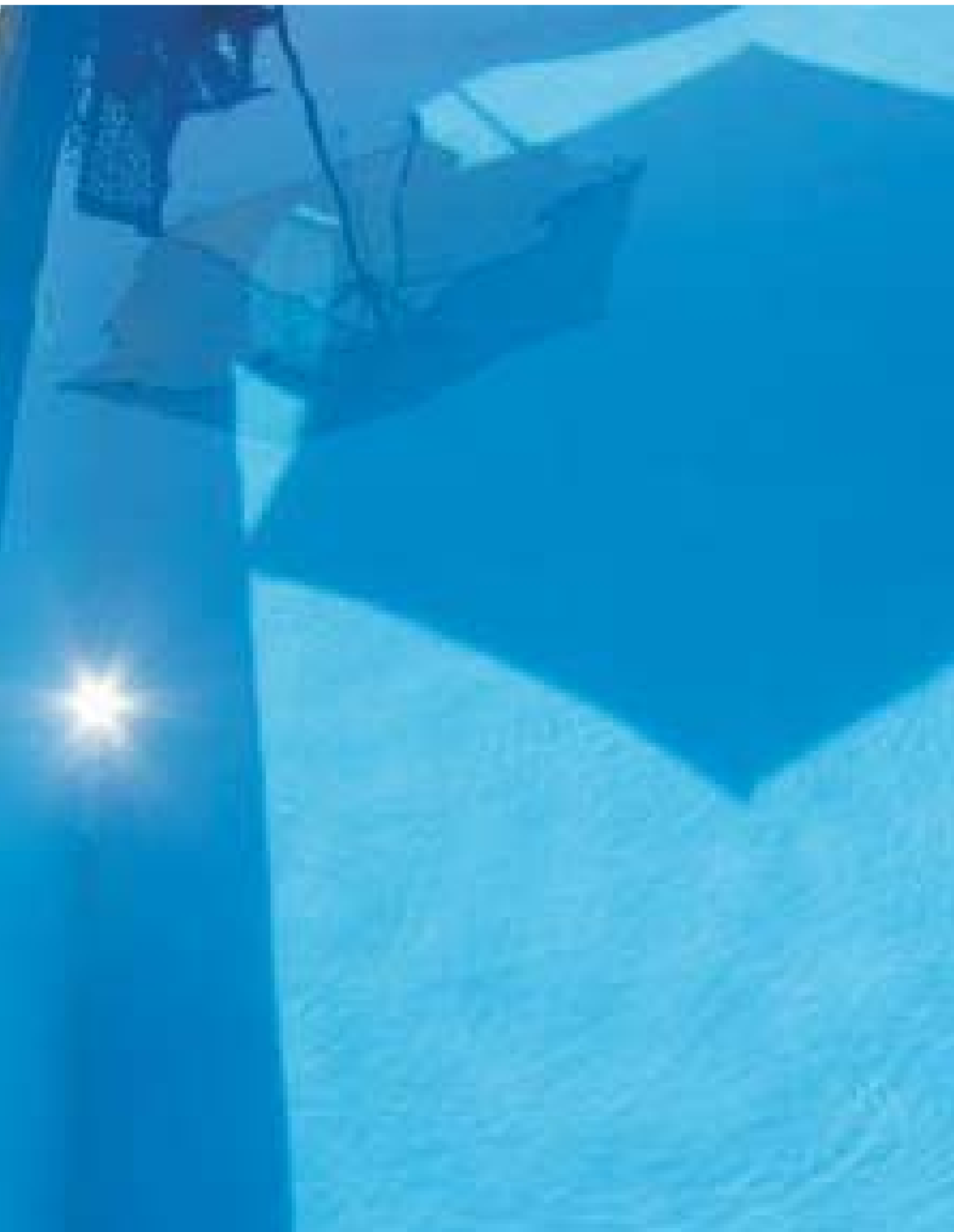

